\title{
Evaluation of the iHEART mental health education programme on resilience and well-being of UK secondary school adolescents
}

\author{
Structured Abstract: \\ Purpose \\ There is abundant evidence of impaired mental well-being in adolescents and young adults. We present the \\ findings of a preliminary study based on a novel structured mental health education programme - Innate Health \\ Education and Resilience Training (iHEART) - in a cohort of secondary school adolescents in the UK.

\section{Methodology}

A curriculum-based 10-week programme was delivered by trained facilitators. 205 students enrolled in the study. An additional 64 participants were within an age-matched non-intervention control group. A nonrandomised control mixed methodology approach was used. All students, pre- and post-programme, completed a quantitative questionnaire - the Warwick-Edinburgh Mental Well-being Survey. Qualitative measures were used to assess participants' perceptions of changes in their resilience and mental well-being.

\section{Findings}

Those who received the intervention showed a small improvement in mental well-being relative to those who did not; with a similar change in resilience. Qualitative findings regarding impulse control and emotional resilience provided positive findings. 


\section{Originality/Value}

iHEART may be a promising new intervention offering a step change in mental health education for improving resilience, mental well-being and the ability for participants to navigate psychological challenges. 


\section{Evaluation of the iHEART mental health education programme on resilience and well-being of UK secondary school adolescents}

One in 8 children and adolescents overall have at least 1 mental disorder (NHS Digital, 2018). A study of 13,600 students aged 7 to 18 found that those who presented depressive symptoms had poorer education results than non-depressed students (Lopez et al. 2019). In addition, the needs of young people are yet to be met, as many are seeking advice for behavioural and social issues (Coverdale, 2017). Current adolescent mental health services fail to meet young people's need (Collins et al, 2017), thus new approaches are needed.

Well-being and resilience interventions are important in the prevention and reduction of mental health problems (Fenwick-Smith et al, 2018). Rutter pioneered the challenge model of resiliency, whereby exposure to certain level of risks enabled youth to overcome subsequent exposures reducing their vulnerability to adverse events (Rutter, 1987). 'Resilience' refers to the process of overcoming the negative effects of risk exposure, coping successfully with traumatic experiences, and avoiding the negative trajectories associated with risks; including 2 promotive factors Assets and Resources -. 'Assets' are factors that reside within individuals, whilst 'Resources' are external factors to an individual, such as parental support, mentors, and youth programmes, (Fergus and Zimmerman, 2005).

The evidence on school-based programmes that promote social and emotional learning (SEL) includes benefits such as improved mental health, emotional well-being, social functioning, heathy behaviour and academic performance, as well as the prevention of negative behaviours (Barry, Clarke \& Dowling, 2017). This paper highlights the work of Innate Health Education and Resilience Training or iHEART, a novel curriculum-based intervention. It has already reached over 100 schools benefiting 4443 young people to date. 


\section{'Three Principles' based mental health education programmes}

There is an emergent form of mental health education known as the Three Principles which is associated with iHEART's methodology. The Three Principles based approach is grounded in the work of Banks (2001).

The approach is about 'understanding the logic of how the mind works' and has been described in detail elsewhere (Kelley, Pransky, \& Lambert, 2015). In brief, it frames life experiences from within via the principles of mind, thought and consciousness, and that recognising the indivisible relationship between thought and feeling is what allows a person's innate mental health to flourish. Emerging evidence suggests that Three Principles based mental health education, may see improvements in mental well-being along with resilience (Kessel et al. 2017).

The following hypotheses were used in this study:

Compared with a control group, students receiving the iHEART mental health education programme will show a significant improvement in:

Hypothesis 1: Mental well-being.

Hypothesis 2: Psychological resilience.

A descriptive paper outlining the curriculum and the training involved to deliver the programme to students, can be found on iHEART's website (https://www.iheartprinciples.com/wp-content/uploads/2020/10/iheartEvidence-Impact-Report-Sept2020.pdf, Appendix A pg30,[Accessed 20.11.20]. 


\section{iHEART Structure}

The iHEART programme is housed by a London, UK-based charity, iHEART Principles. The curriculum was co-created by Terry Rubenstein (head of iHEART education) and Dana Arenson in 2017. The charity is funded by multiple grants including the National Lottery and the Mayor of London's Young Londoners' Fund. iHEART facilitators come from multi-disciplinary backgrounds are trained using a comprehensive, highly structured, replicable programme.

\section{Design}

A non-randomised control mixed methodology approach was used. Quantitative measures were taken to assess potential changes in participants' mental well-being and resilience from pre- to post-intervention. Qualitative questions measured participants' understanding of the intervention and what they believed had changed within themselves as a result. Both sets of findings were used to complement one another in the form of triangulation (Johnson \& Onwuegbuzie, 2004).

\section{Participants}

205 participants aged 11-15 provided a full set of matching pre and post evaluation data of the iHEART Curriculum. 169 of the participants were male, 12 were female, and 24 had missing data An additional 64 children were within a control group. Gender differences were due to majority of participants coming from all boys' schools including the control group. Participants were from 6 different schools based in London:. 5

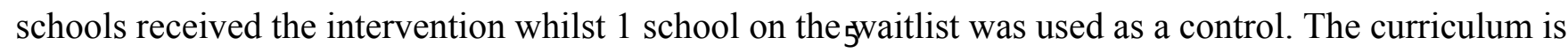


currently standardised across the age ranges in this study. Power analysis indicated a power of .822 based on a small effect size, $\alpha$ of 0.05 and a large correlation effect size between pre-intervention and post-intervention measures.

\section{Intervention}

The intervention was a compulsory part of their timetable covering the UK governement's required Relationships and Sex Education (RSE); students and parents received a letter to opt out of the research. The iHEART programme is a structured, sequential set of 50-minute sessions over 10 consecutive weeks, delivered during regular school hours each by 2 facilitators. The first 6 sessions discuss the way the mind operates, building through a "scaffold" approach to learning an understanding of the human psychological system. The next 4 sessions focus on an application of this understanding to real-life issues of relevance to the age group of participants such as exam stress, anxiety, managing social media, and bullying. Each session is broken down into sections: key learning objectives, bridging, the 'Big Idea', activities and wrap up. For example, the metaphor of a tea bag transforming to tea by hot water is used to illustrate how thought is enlivened by consciousness. Sessions include animations, video clips, exercises, games and practical groupbased activities. The iHEART Online Resource Portal (IRP) provides consistent delivery resources amongst facilitators.

\section{Measures}

\section{A) Quantitative:}

The Warwick-Edinburgh Mental Well-being Scale (WEMWBS) comprises 12 items measuring wellbeing/self-esteem. The WEMWBS has good psychometric properties; its outcome relationships have reported 
relatively high correlations with the other well-being measures (correlations $\geq 0.7$ ), and moderate negative correlations with the measures of mental ill-health (Stewart-Brown et. al., 2009).

The Inside-Out Resilience Questionnaire (I-ORQ) has been uniquely developed in-house as a novel means to match the content of the iHEART programme to its internal validation and outcome quantification and contains 12 items measuring resilience with responses are made on a 5-point Likert scale ranging from 1 (strongly disagree) to 5 (strongly agree). Item responses are summed for a total I-ORQ score. The internal consistency reliability coefficient is 0.60 .

\section{B) Qualitative:}

3 Qualitative questions - to assess subjective impact of the course - were constructed and administered immediately post-course to active participants, with classroom teachers in attendance; 1) "Have you noticed any change in yourself since this programme started?" and, if yes; 2) "What do you think caused the change?". Finally, they were asked 3) "Would you recommend this programme to a friend"?

\section{Ethics}

Ethical approval was granted from a UK Higher Education Institution in the academic year 2017/18. School, parental, and student consent was gained including the potential for data analysis related to academic and nonacademic purposes. All data was maintained securely and in line with GDPR (General Data Protection Regulation). 


\section{Results}

\section{A) Quantitative Data}

To answer the question of whether the iHEART intervention had a positive impact on well-being and resilience a Mixed Factorial ANOVA was conducted. This allows us to look at the possible interaction connecting the between measures variable of group (iHEART vs Control) and the within measures variable (pre and post intervention). Prior to statistical analysis the assumptions required for an ANOVA were tested and all were met.

\section{Hypothesis 1: Mental Well-being.}

\section{Mental Well-being}

Statistics for the outcome variable of well-being, measured using WEMWBS, can be found in Figure 1.

Figure 1: Average well-being data for the iHeart vs control group before and after receiving the curriculum (higher scores = greater well-being).

\begin{tabular}{|c|c|c|c|c|c|c|c|c|}
\hline \multirow[b]{3}{*}{ Well-being } & \multicolumn{4}{|c|}{ iHeart } & \multicolumn{4}{|c|}{ Control } \\
\hline & \multirow[b]{2}{*}{ Mean } & \multirow[b]{2}{*}{ SD } & \multicolumn{2}{|c|}{$\begin{array}{l}\text { 95\% Confidence } \\
\text { Intervals }\end{array}$} & \multirow[b]{2}{*}{ Mean } & \multirow[b]{2}{*}{ SD } & \multicolumn{2}{|c|}{$\begin{array}{l}\text { 95\% Confidence } \\
\text { Intervals }\end{array}$} \\
\hline & & & Lower & Upper & & & Lower & Upper \\
\hline $\begin{array}{c}\text { Pre- } \\
\text { Intervention }\end{array}$ & 3.38 & 0.56 & 3.31 & 3.46 & 3.52 & 0.56 & 3.38 & 3.66 \\
\hline $\begin{array}{c}\text { Post- } \\
\text { Intervention }\end{array}$ & 3.48 & 0.60 & 3.39 & 3.561 & 3.36 & 0.68 & 3.19 & 3.53 \\
\hline
\end{tabular}




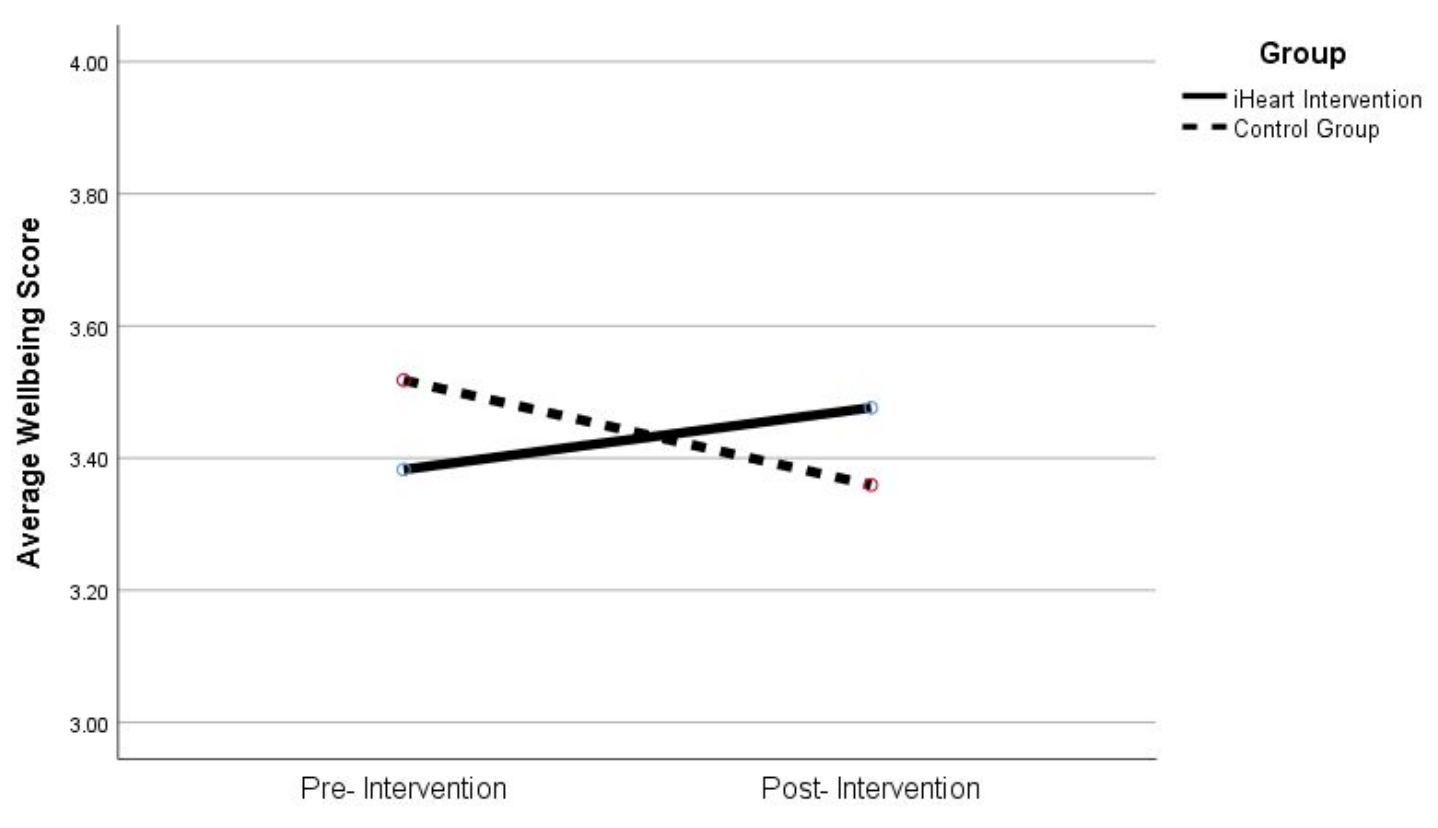

The well-being scores for the iHEART group showed an increase from baseline scores before receiving the iHEART Curriculum to after completing the iHEART Curriculum. The increase was minor with a small effect size $r=.101$. The well-being scores for the control group (who did not receive the iHEART intervention) showed a decrease in well-being from pre to post intervention with a small effect size $r=.114$.

A 2 x 2 Mixed factorial ANOVA indicated no significant main effect of time $F(1,266)=.542, \mathrm{p}=.424, \eta_{p}^{2}=$ .002 ; and no significant main effect of group $\mathrm{F}(1,266)=0.015, \mathrm{p}=.902, \eta_{p}^{-\frac{2}{p}}<.001$. There was, however, a significant interaction between time and group: $\mathrm{F}(1,266)=9.654, \mathrm{p}=.002, \eta_{p}^{2}=.035$. Simple effects analysis highlighted this difference between iHEART and control group post evaluation only with a small effect size $r=$ 0.17. The difference between iHEART and control groups pre- intervention was non-significant $(r=0.04)$.

The relative decrease in well-being over time for the control group and the increase in well-being over time for the iHEART groups is shown in Figure 1. Results highlight that, on average, those who received the intervention reported an improvement in well-being scores post intervention, in contrast to participants who did not receive the intervention during the same time frame (See Figure 1.) 


\section{Hypothesis 2: Psychological Resilience.}

\section{Psychological Resilience}

The bespoke Inside-Out Resilience Questionnaire (I-ORQ) did not reach a satisfactory internal consistency. Therefore, a factor analysis was conducted to assess if some of the items could be unified as a scale.

Exploratory factor analysis using varimax rotation indicated that 6 of the 12 items could be clustered into one factor assessing aspects most closely related to the iHEART intervention (i.e. other people make me feel bad/good about myself; things that happen in my life affect how I feel; social media impacts how I feel about myself; when I am bullied it makes me feel bad; exams make me feel stressed; feeling anxious is a bad thing). The 6 items had a Cronbach alpha reliability of .603 at time 1 and .635 at time 2 . This is still considered under the threshold for reliability (Nunnally, 1978) and therefore, results must be treated with caution.

Statistics for the outcome variable using the 6 items indicated by the factor analysis can be found in Figure 2 . A higher number equates to lower levels of resilience.

Figure 2: Average resilience data for the iHEART vs control group before and after receiving the curriculum (lower scores $=$ greater resilience).

\begin{tabular}{|c|c|c|c|c|c|c|c|c|}
\hline \multirow[b]{3}{*}{ Resilience } & \multicolumn{4}{|c|}{ iHeart } & \multicolumn{4}{|c|}{ Control } \\
\hline & \multicolumn{4}{|c|}{$\begin{array}{l}95 \% \text { Confidence } \\
\text { Intervals }\end{array}$} & \multirow[b]{2}{*}{ Mean } & \multirow[b]{2}{*}{ SD } & \multicolumn{2}{|c|}{$\begin{array}{l}\text { 95\% Confidence } \\
\text { Intervals }\end{array}$} \\
\hline & Mean & SD & Lower & Upper & & & Lower & Upper \\
\hline $\begin{array}{c}\text { Pre- } \\
\text { Intervention }\end{array}$ & 3.38 & 0.63 & 3.29 & 3.47 & 3.35 & 0.60 & 3.21 & 3.51 \\
\hline $\begin{array}{c}\text { Post- } \\
\text { Intervention }\end{array}$ & 3.19 & 0.67 & 3.10 & 3.29 & 3.47 & 0.56 & 3.33 & \\
\hline
\end{tabular}




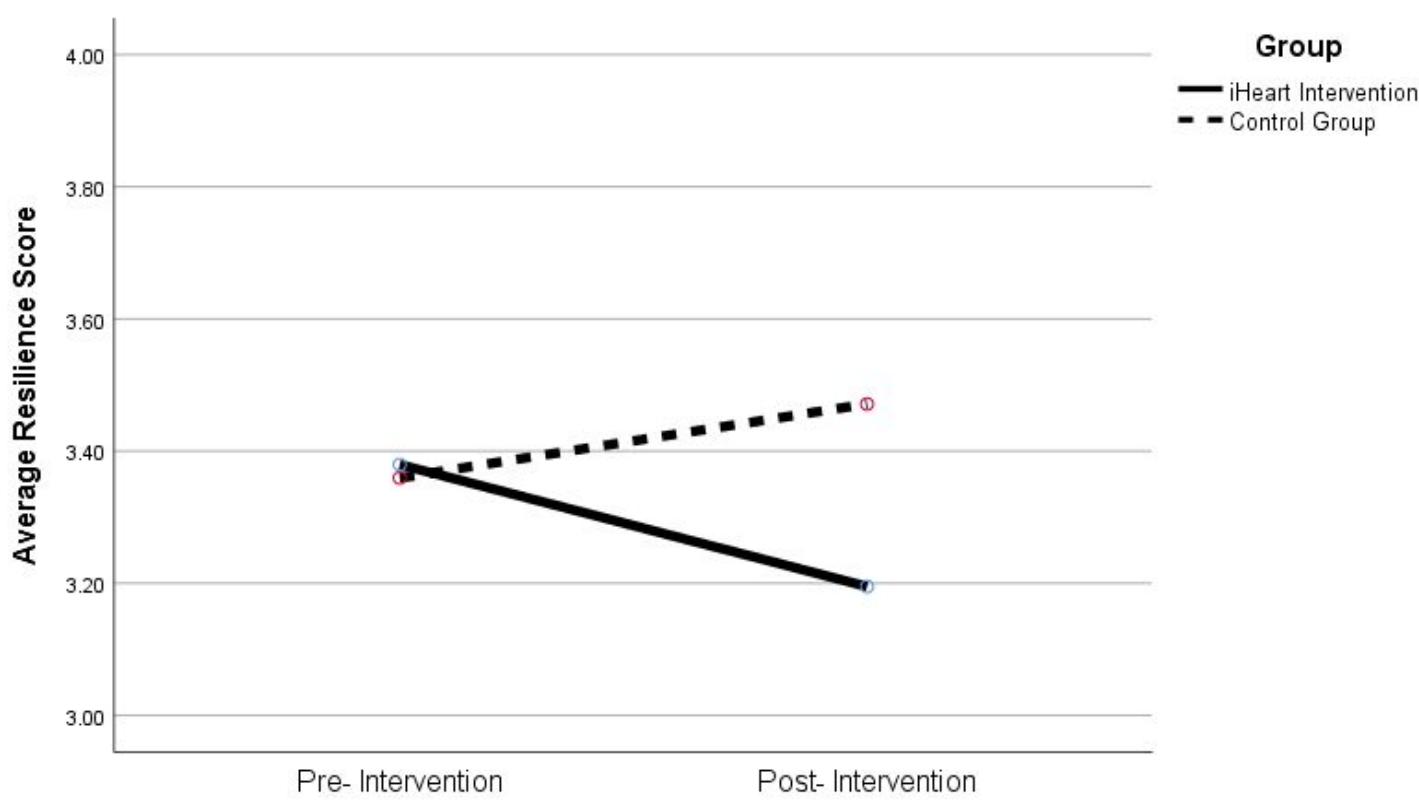

As can be seen in Figure 2, the resilience scores for the iHEART group showed decrease in scores from baseline scores (improved resilience) in terms of before and after curriculum delivery. The decrease was small to medium in effect size $r=.14$. The I-ORQ scale scores for the control group (who did not receive the iHEART intervention) showed an increase from pre to post intervention with a small effect size $r=.10$ highlighting a decrease in resilience levels.

A 2 x 2 Mixed Factorial ANOVA indicated no significant main effect of time $\mathrm{F}(1,265)=0.619, p=.432, \eta_{p}^{-}=$ .002 ; and no significant main effect of group $\mathrm{F}(1,265)=2.656, p=.104, \eta_{p}^{2}=.010$.

There was, however, a significant interaction between time and group: $\mathrm{F}(1,265)=10.335, p=.001, \eta_{p}^{-}=.038$. Simple effects analysis highlighted this difference was between experimental and control group, post evaluation only, with a small to medium effect size $r=0.22$. The difference between experimental and control group preintervention was non-significant $(r<0.01)$. Results highlight that, on average, following the intervention, 
participants reported less impact of other people on their thoughts and feelings than before the intervention as well as in comparison to the control group (Figure 2).

\section{B) Qualitative Data}

Latter groups partaking in iHEART were also asked to complete a set of open-ended qualitative questions in class. In total 82 participants completed these questions. Qualitative responses were analysed and interpreted using 6-stage thematic analysis (Braun and Clarke 2006). The questions highlighted similar themes and therefore they could be analysed and interpreted as one. Predominant themes in response to questions were improvements in 1) Impulse Control; and 2) Emotional Resilience. Overall, 95\% $(n=78)$ indicated that they would recommend the programme to friends.

\section{Impulse Control}

Several students spoke specifically around control over certain negative behaviours such as anger, frustration and impulsive acts and some mentioned beneficial changes that lead to improved emotional coping strategies.

"I have been able to stop myself from losing my temper or getting angry"

\section{Emotional Resilience}

Students highlighted a clear insight that emerged post intervention, , as demonstrated by a more resilient response as shown in the response below.

"I have noticed a different response to things that I had viewed as bad and realised that they were just thoughts." 


\section{Discussion}

The purpose of this study was to assess the efficacy of iHEART for improving the mental well-being and resilience of UK secondary school students. The study's quantitative findings showed a small positive shift for the intervention group, relative to the non-intervention group, although this shift was not significant. Responses to the qualitative items reported some heightened level of emotional mastery. Taken together, the quantitative and qualitative results are encouraging. Evidence suggests positive effects of SEL interventions do last, but diminish over time (Taylor et al 2017). Therefore, future research will address individual differences and incorporate lengthier follow-up times, to better specify effect sizes.

\section{Limitations}

This study has several limitations. It was predominantly conducted amongst boys; hence the gender-related impact of this work needs more detailed assessment. Furthermore, measurements were made immediately postintervention only, meaning no conclusions can be drawn regarding the long-term impact of iHEART. Additional studies would need to evaluate relevance of different times of the year, plus the role of age and gender. Future work will assess impact on other school related variables such as exclusion rates, disruptive behaviour and educational attainment. 


\section{Conclusions}

Mental health-related programmes can be delivered in schools; common characteristics of successful programmes include defined goals, active learning, dedicated time/lessons, step-by-step guidelines and clear theoretical foundations. (Demkowicz and Humphrey, 2019).

Young people participating in the iHEART programme are not taught to "disengage" from their minds; rather, students are taught an understanding of their psychological system, and how to navigate and problem-solve through negative experiences. While it is a provision of educational tools to aid in the building of resilience and the prevention of an increase in mental illness, it is not intended to cure it. In conclusion, iHEART shows promising results in improving the mental well-being and psychological resilience of adolescents. Further work is taking place to establish more precise outcomes.

\section{References}

Banks, S. (2001). The enlightened gardener. Vancouver, BC: Lone Pine. Publishing.

Barry, M.M., Clarke, A.M. and Dowling, K., (2017). Promoting social and emotional well-being in schools. Health Education. Vol. 117 No. 5, pp. 434-451

Braun, V. and Clarke, V., (2006). Using thematic analysis in psychology. Qualitative research in psychology, 3(2), .77-101. 
Collins, R., Notley, C., Clarke, T., Wilson, J. and Fowler, D., (2017). Participation in developing youth mental health services: "Cinderella service” to service re-design. Journal of Public Mental Health. vol. 16, no. 4, pp. $159-168$

Coverdale, G., (2017). The importance of well-being in children and young people. Journal of Public Mental Health. Vol. 16 No. 3, pp. 93-95

Demkowicz, O. and Humphrey, N., (2019). Whole School Approaches to Promoting Mental Health: What Does The Evidence Say? https://www.ucl.ac.uk/evidence-based-practice-unit/sites/evidence-basedpractice-unit/files/evidencebriefing5_v1d7_completed_06.01.20.pdf [Accessed 2.8. 2020].

Fenwick-Smith, A. Dahlberg EE, Thompson SC, (2018) Systematic review of resilience-enhancing, universal, primary school-based mental health promotion programs. BMC Psychol. Jul 5;6(1):30

Fergus, S., \& Zimmerman, M. A. (2005). Adolescent resilience: A framework for understanding healthy development in the face of risk. Annu. Rev. Public Health, 26, 399-419.

Johnson, R.B. and Onwuegbuzie, A.J., (2004). Mixed methods research: A research paradigm whose time has come. Educational researcher, . 33(7), 14-26.

Kelley, T. M., Pransky, J., \& Lambert, E. (2015). Realizing improved mental health through understanding three spiritual principles. Spirituality in Clinical Practice, 2(4), 267-281.

Kelley, T. M., Hollows, J., \& Savard, D. (2019). The efficacy of intensive three principles correctional counseling for improving the mental health/resilience of people in an English prison. Journal of Offender Rehabilitation, 58(8), 661-677.

Kessel, A. Neill, M. Marmur, E. Malik, R. (2017) "A superpower? An educational initiative? Or something else Journal of Public Mental Health, 16 (4), 169-171.

Lopez J.A et al (2019). How depression relates to academic achievement in adolescence and early adulthood: identifying high risk points. Policy Bristol, University of Bristol 
NHS Digital. (2018). Mental health of Children and Young People in England, 2017. https://digital.nhs.uk/dataand-information/publications/statistical/mental-health-of-children-and-young-people-in-england/2017/2017

[Accessed 15.11.2020]

Nunnally, J.C., (1978). An overview of psychological measurement. In Clinical diagnosis of mental disorders (pp. 97-146). Springer, Boston, MA.

Rutter, M. (1987). Psychosocial resilience and protective mechanisms. American Journal of orthopsychiatry, 57(3), 316-331.

Stewart-Brown S, Tennant A, Tennant R, Platt S, Parkinson J, Weich S. (2009) Internal construct validity of the Warwick-Edinburgh Mental Well-being Scale (WEMWBS): a Rasch analysis using data from the Scottish Health Education Population Survey. Health Qual Life Outcomes. Feb 19; 7:15.

Taylor, R., Oberle, E., Durlak, J. and Weissberg, R., (2017). Promoting Positive Youth Development Through School-Based Social and Emotional Learning Interventions: A Meta-Analysis of Follow-Up Effects. Child Development, 88(4), pp.1156-1171. 
Figures

Figure 1: Average well-being data for the iHeart vs control group before and after receiving the curriculum (higher scores $=$ greater well-being).

\begin{tabular}{|c|c|c|c|c|c|c|c|c|}
\hline \multirow[b]{3}{*}{ Wellbeing } & \multicolumn{4}{|c|}{ iHeart } & \multicolumn{4}{|c|}{ Control } \\
\hline & \multirow[b]{2}{*}{ Mean } & \multicolumn{3}{|c|}{$\begin{array}{l}\text { 95\% Confidence } \\
\text { Intervals }\end{array}$} & \multirow[b]{2}{*}{ Mean } & \multirow[b]{2}{*}{ SD } & \multicolumn{2}{|c|}{$\begin{array}{l}\text { 95\% Confidence } \\
\text { Intervals }\end{array}$} \\
\hline & & SD & Lower & Upper & & & Lower & Upper \\
\hline $\begin{array}{c}\text { Pre- } \\
\text { Intervention }\end{array}$ & 3.38 & 0.56 & 3.31 & 3.46 & 3.52 & 0.56 & 3.38 & 3.66 \\
\hline $\begin{array}{c}\text { Post- } \\
\text { Intervention }\end{array}$ & 3.48 & 0.60 & 3.39 & 3.561 & 3.36 & 0.68 & 3.19 & 3.53 \\
\hline
\end{tabular}

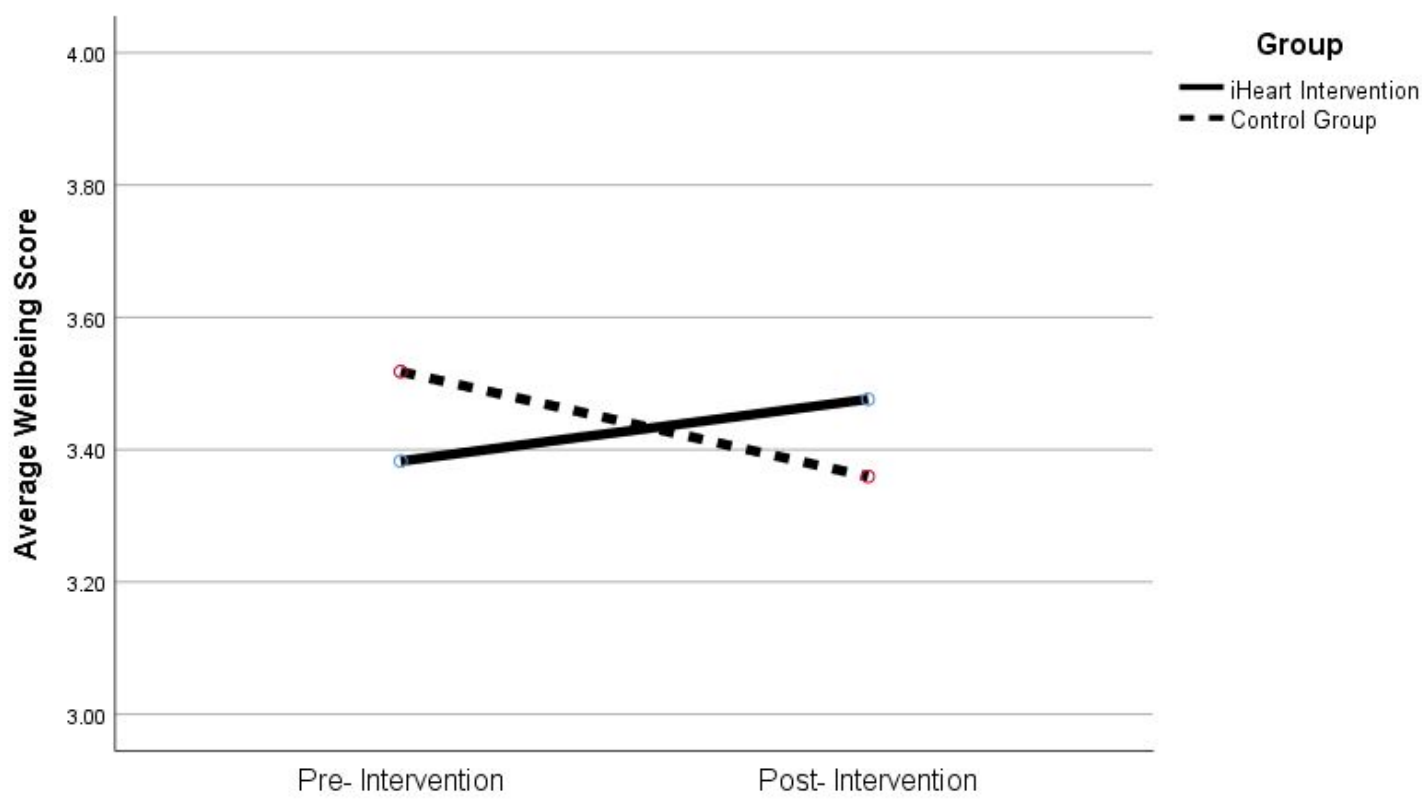


Figure 2: Average resilience data for the iHEART vs control group before and after receiving the curriculum (lower scores $=$ greater resilience).

\begin{tabular}{|c|c|c|c|c|c|c|c|c|}
\hline \multirow[b]{3}{*}{ Resilience } & \multicolumn{4}{|c|}{ iHeart } & \multicolumn{4}{|c|}{ Control } \\
\hline & \multicolumn{4}{|c|}{$\begin{array}{l}\text { 95\% Confidence } \\
\text { Intervals }\end{array}$} & \multirow[b]{2}{*}{ Mean } & \multirow[b]{2}{*}{ SD } & \multicolumn{2}{|c|}{$\begin{array}{l}\text { 95\% Confidence } \\
\text { Intervals }\end{array}$} \\
\hline & Mean & SD & Lower & Upper & & & Lower & Upper \\
\hline $\begin{array}{c}\text { Pre- } \\
\text { Intervention }\end{array}$ & 3.38 & 0.63 & 3.29 & 3.47 & 3.35 & 0.60 & 3.21 & 3.51 \\
\hline $\begin{array}{c}\text { Post- } \\
\text { Intervention }\end{array}$ & 3.19 & 0.67 & 3.10 & 3.29 & 3.47 & 0.56 & 3.33 & \\
\hline
\end{tabular}

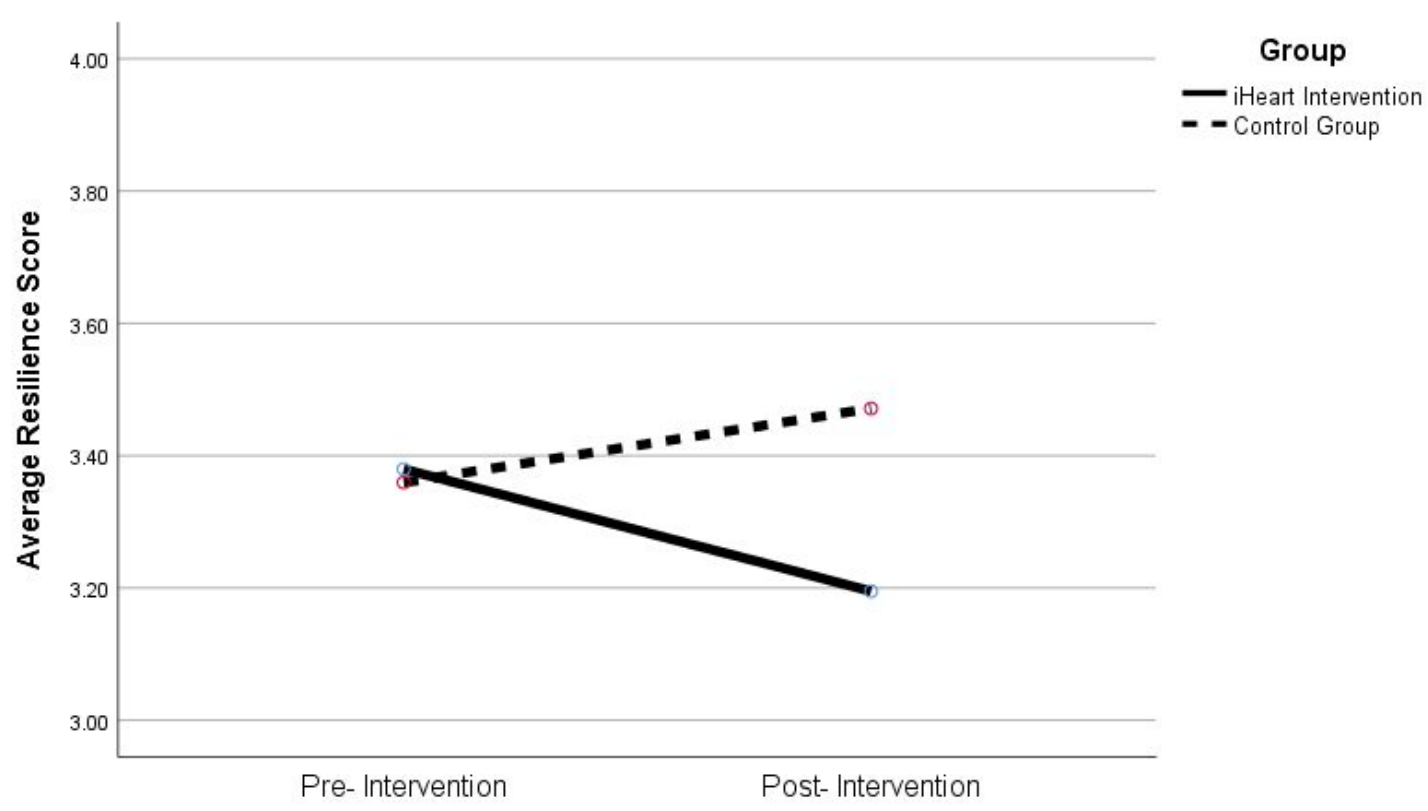

